\title{
Improved Performance of an Asynchronous Motor Drive with a New Modified Incremental Conductance based MPPT Controller.
}

\author{
${ }^{1}$ Jadav Pravalika, ${ }^{2}$ Dr. Pakkiraiah B, ${ }^{3} M$. Rekha \\ ${ }^{1} \mathrm{M}$. Tech Research Scholar, GRIET, Department of EEE, Hyderabad, India \\ ${ }^{2}$ Associate Professor, GRIET, Department of EEE, Hyderabad, India \\ ${ }^{3}$ Assistant Professor, GRIET, Department of EEE, Hyderabad, India
}

\begin{abstract}
This paper describes the improved performance of an asynchronous motor drive with a new modified Incremental conductance-based MPPT controller. In the last few decades, renewable energy sources are playing a dominant role in electricity generation as non-renewable energy sources are becoming extinguish and are the major cause of global warming. Photovoltaic (PV) energy is the most important energy resource since it is clean, pollution-free, and inexhaustible. Maximum power point tracking (MPPT) is used in photovoltaic systems to maximize the photovoltaic array output power with variable irradiances and variable temperature. The space vector modulation technique is used to reduce ripple content and fluctuation with improving efficiency. The algorithm used in MPPT is the Incremental Conductance method for a solar PV system to determine maximum output power.

Keywords - Solar PV system, MPPT controller, Incremental conductance method, Space vector modulation (SVM), Boost converter.
\end{abstract}

\section{INTRODUCTION}

As of now, we are using a conventional source of power supply but in the future, we will go for the nonconventional source of supply due to lack of supply from the conventional and many researchers are looking forward to having the efficient and better enhancement regarding the non-conventional i.e., renewable energy sources by which the global warming can be reduced. The new merging techniques are being developed for various structures of the PV system. The long-term sustained energy source is a renewable energy source, India aims to install $175 \mathrm{GW}$ of renewable capacity by 2022 , and of which $100 \mathrm{GW}$ is outlined for solar power and at an annual average rate of $16 \%$ is expected to grow between 2018 and 2026 [1-3]. To better understand the performance of the Solar PV system, mathematical modelling has been used [4-5]. PV modules are connected in series and parallel to provide additional output voltage and current in a PV array. The photovoltaic effect is used to generate electricity in solar PV systems [6].

The efficiency of energy conversion for PV module lies in between $12 \%-20 \%$. These losses are also affected by PV system analysis based on temperature, irradiation, and associated loads. At required load conditions, an MPPT controller in combination with a DC boost converter can overcome the maximum power point voltage [7-9]. However, the maximum power point of a PV array varies with the weather. Thus it is an important task to obtain and maintain the maximum power point (MPP) as constant by using MPPT controllers. Due to the unpredictability of solar energy supplies, maximum power point tracking is required to ensure that a photovoltaic system operates continuously at MPP [10-11]. Various MPPT approaches are developing, each with its own perspective on how to improve PV system performance. In tracking for rapid transient weather conditions, each application has its own set of benefits, drawbacks, and limitations. [12-14].

The sensed voltage and currents of the PV array are used for feeding the load demand with the help of a boost converter and a three-phase inverter. Several strategies are being used for the selecting order of vectors to reduce the switching losses and the harmonic content [15-17]. An SVM is an algorithm used to control the pulse width modulation by having six sectors in which de supply is converted to ac waveform to drive three-phase AC powered motors at varying speeds. Thus it is implemented by properly choosing and performing switching conditions of carrier wave with reference wave for generating pulses[18-20]. The space vector pulse width modulation technique is being used for controlling the inverter pulses by which the distortions in output voltage and current can be reduced with fast switching, reduction in losses, and better performance for high efficiency.

This paper is proposed to improve the performance parameters of the asynchronous motor by reducing the ripple content in torque and speed characteristics and also 
boost up voltage and current coming from the PV array with the boost converter and also drive the motor with 3ph inverter with SVM technique. Several MPPT techniques are being evolving due to drawbacks in attaining maximum power at varying temperature and irradiance conditions. These leads to slowing tracking and fluctuations during rapidly changing whether conditions, which affects the utilization efficiency to overcome this incremental conductance MPPT controller algorithm is implemented under different working conditions. In section 2, mathematical modeling of PV array is being discussed. Section 3 gives a detailed explanation about the project implementation with the proposed MPPT algorithm and Space vector modulation based inverter fed to the induction motor drive. Matlab simulation \& obtained results are presented in section 4 and the concluding remarks are being stated in section 5 .

\section{MATHEMATICAL MODELING OF PV ARRAY}

All photovoltaic cells are gathering to form a solar photovoltaic system. These Cells are grouped in series and parallel to produce higher voltages, currents, and power levels. In the below figure, PV generated current is described by the following equation.

$$
\mathrm{I}_{\mathrm{pv}}=\mathrm{I}_{\mathrm{m}}-\mathrm{I}_{\mathrm{sh}}
$$

Where $\mathrm{I}_{\text {sh }}$ is the current through shunt resistor given by

$$
\begin{aligned}
& I_{s h}=\frac{\left(V_{p v}+I_{p v} \cdot R_{S}\right)}{R_{p}} \\
& \mathrm{I}_{\mathrm{m}}=\mathrm{I}_{\mathrm{g}}-\mathrm{I}_{\mathrm{d}}
\end{aligned}
$$

Here $R_{s}$ and $R_{p}$ are the series resistance and parallel resistance in the circuit given as $0.221 \Omega$ and $360.002 \Omega$.

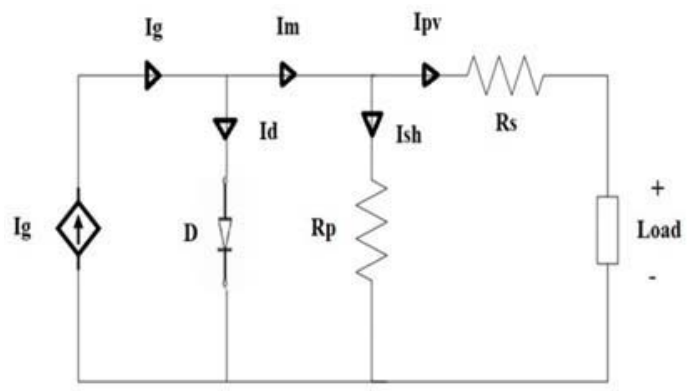

Fig.1 PV cell equivalent circuit

Where $I_{g}$ is the generated PV current proportional to solar irradiation given by

$$
I_{g}=\left(I_{s c}+K_{i} \times\left(T-T_{n}\right)\right) \times G / G_{n}
$$

Where: $I_{g}$ is the photo-current or light generated curent in $\mathrm{A}, \mathrm{I}_{\mathrm{sc}}$ is short circuit current of the module given as 9.10 Amps, $\mathrm{q}$ is electron charge at $1.602 \times 10^{-19} \mathrm{C}, \mathrm{K}$ is the Boltzmann's constant at $1.381 \times 10^{-23} \mathrm{~J} / \mathrm{K}, \mathrm{K}_{\mathrm{i}}$ is short circuit current of a cell at STC, G is applied solar irradiance in $\mathrm{W} / \mathrm{m}^{2}, \mathrm{G}_{\mathrm{n}}$ is the reference solar irradiance in $\mathrm{W} / \mathrm{m}^{2}$ (taken under STC as $1000 \mathrm{~W} / \mathrm{m}^{2}$ ).

The diode saturation current is given by

$$
I_{d}=I_{r s} \times\left(\frac{T}{T_{n}}\right)^{3} \times \exp \left\{\frac{q E_{g O}}{n K}\left(\frac{1}{T_{n}}-\frac{1}{T}\right)\right\}
$$

Where, $\mathrm{I}_{\mathrm{rs}}=$ Reverse saturation current of a diode in Amps.

$\mathrm{n}=$ Diode ideality factor (i.e., 1.3).

$\mathrm{T}=$ Applied temperatures of the PV module in kelvin.

$\mathrm{T}_{\mathrm{n}}=$ Ref temperature for the PV module in kelvin.

$\mathrm{E}_{\mathrm{g} 0}=$ Bandgap energy of the module (i.e., 1.1).

The reverse saturation current of the diode is given by

$$
I_{r s}=\frac{I_{S C}}{\exp \left(\frac{q V_{O C}}{N_{t} K n T}\right)-1}
$$

Where, $\mathrm{V}_{\mathrm{oc}}=$ Open circuit voltage of PV module in volts (i.e., 45.70 volts)..

$\mathrm{N}_{\mathrm{t}}=$ Total no. of cells in a module are 72.

TABLE. I Module Power Values at Distinct Irradiance and Distinct Temperature.

\begin{tabular}{|c|l|l|l|l|l|}
\hline \multirow{2}{*}{$\begin{array}{c}\text { Irradian } \\
\text { ce in } \\
\left(\mathbf{W} / \mathbf{m}^{2}\right)\end{array}$} & \multicolumn{5}{|c|}{ Temperature (in $\left.{ }^{\circ} \mathbf{C}\right)$} \\
\cline { 2 - 6 } & $\mathbf{2 0}^{\circ} \mathbf{C}$ & $3^{\circ} \mathbf{C}$ & $\mathbf{4 0}^{\circ} \mathbf{C}$ & $\mathbf{5 0}^{\circ} \mathbf{C}$ & $\mathbf{6 0}^{\circ} \mathbf{C}$ \\
\hline 1000 & 393.984 & 394.027 & 394.069 & 394.113 & 394.156 \\
\hline 800 & 311.352 & 311.249 & 311.144 & 311.039 & 310.934 \\
\hline 500 & 189.545 & 189.299 & 189.050 & 188.862 & 188.552 \\
\hline 250 & 91.048 & 90.793 & 90.532 & 90.275 & 90.012 \\
\hline 100 & 34.450 & 34.276 & 34.102 & 33.926 & 33.750 \\
\hline 50 & 16.479 & 16.36 & 16.251 & 16.138 & 16.021 \\
\hline 10 & 2.9502 & 2.9125 & 2.8798 & 2.8437 & 2.8058 \\
\hline & & & & & \\
\hline
\end{tabular}

We can observe those module voltages are decreasing as the applied temperature goes on increasing which can be calculated by given equation.

$$
V_{p v}=\frac{N_{t} K n T}{q} \times \ln \left[\frac{I_{g}-I_{r s}}{I_{r s}}\right]
$$

Final expression for PV cell output current is given by

$$
I_{p v}=I_{g}-I_{d}\left[\exp \frac{q\left(V_{p v}+I_{p v} \cdot R_{s}\right)}{N_{t} K n T}-1\right]-I_{s h}
$$

Where, $\mathrm{V}_{\mathrm{pv}}=$ Module voltage in volts .

$\mathrm{I}_{\mathrm{pv}}=\mathrm{PV}$ module current in amps. 
TABLE. II Array Power Values at Distinct Irradiance and Distinct Temperature.

\begin{tabular}{|c|c|l|l|l|l|}
\hline $\begin{array}{c}\text { Irradiance } \\
\text { in }\left(\mathbf{W} / \mathbf{m}^{2}\right)\end{array}$ & \multicolumn{5}{|c|}{ Temperature (in $\left.{ }^{\circ} \mathbf{C}\right)$} \\
\cline { 2 - 6 } & $\mathbf{2 0}^{\circ} \mathbf{C}$ & $\mathbf{3 0}^{\circ} \mathbf{C}$ & $\mathbf{4 0}^{\circ} \mathbf{C}$ & $\mathbf{5 0}^{\circ} \mathbf{C}$ & $\mathbf{6 0}^{\circ} \mathbf{C}$ \\
\hline 1000 & 2363.90 & 2364.16 & 2364.41 & 2364.67 & 2364.93 \\
\hline 800 & 1868.11 & 1867.49 & 1866.86 & 1866.23 & 1865.60 \\
\hline 500 & 1137.27 & 1135.79 & 1134.30 & 1132.81 & 1131.31 \\
\hline 250 & 546.292 & 544.762 & 543.196 & 541.651 & 540.076 \\
\hline 100 & 206.704 & 205.661 & 204.612 & 203.561 & 202.505 \\
\hline 50 & 98.8747 & 98.2035 & 97.5061 & 96.8296 & 96.1279 \\
\hline 10 & 17.7012 & 17.4754 & 17.2695 & 17.0627 & 16.8350 \\
\hline
\end{tabular}

\section{PROJECT IMPLEMENTATION}

\section{A. BLOCK DIAGRAM}

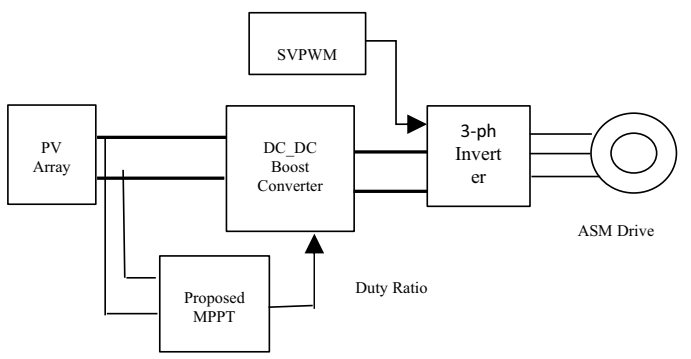

Fig.2 proposed MPPT controller which drives the load.

From the PV module, the sensed voltages and currents were given to the boost converter through the Proposed MPPT controller. Here the proposed MPPT controller is the incremental conductance method used to track the maximum power from the PV array and given to the boost converter. Which boosts up the voltage and, these voltages are feeding to a three-phase inverter as DC voltage. The three-phase inverter converts DC supply to AC supply. where the switching pulses for an inverter were given by the space vector modulation technique. The 3-phase inverter output voltage is fed to an asynchronous motor thereby the performance of the drive is observed and, the characteristics of the PV system are represented in section IV.

\section{B. PROPOSED MPPT ALGORITHM FOR TRACKING}

To get the maximum power out of renewable energy sources, we're going to use certain strategies that help us regulate them and acquire the MPP as we need. Maximum power point tracking (MPPT) methods, are controllers that are utilised in many research activities with wind turbines, photovoltaic (PV) solar systems, and other systems under diverse situations. The flow chart of the proposed MPPT algorithm is illustrated in Fig. 3

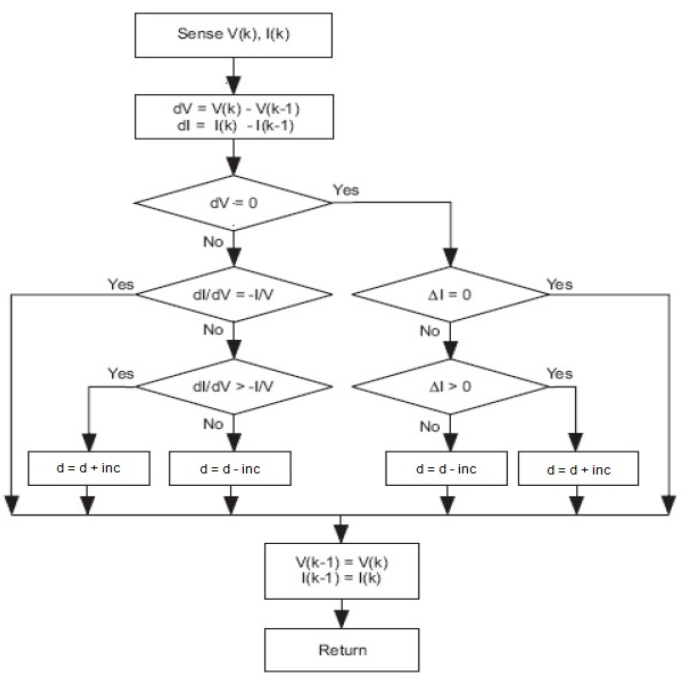

Fig.3 Flow chart of proposed MPPT controller

In this proposed system we are going to use the incremental conductance method, the controller measures incremental changes in PV array current and voltage to predict the effect of a voltage change. This method can track changing conditions more rapidly and it can produce oscillations in power output. To compute the sign of the changes in power concerning voltages $(\mathrm{dP} / \mathrm{dV})$ this method utilizes the incremental conductance $(\mathrm{dI} / \mathrm{dV})$. The incremental conductance method computes the maximum power point by comparing incremental conductance (I $\Delta /$ $\mathrm{V} \Delta)$ to the array conductance $(\mathrm{I} / \mathrm{V})$. When these two are equal (I / V $=\mathrm{I} \Delta / \mathrm{V} \Delta$ ), the output voltage will be MPP voltage. The controller maintains this voltage until the irradiation changes and the process is repeated.

The incremental conductance method is based on the observation that at the MPP $\mathrm{dP} / \mathrm{dV}=0$, and that $\mathrm{P}=\mathrm{IV}$. The characteristic of the power-voltage curve also shows that: when the voltage is small than the maximum power point, $\mathrm{dP} / \mathrm{dV}>0$, so $\mathrm{dI} / \mathrm{dV}>-\mathrm{I} / \mathrm{V}$; when the voltage is large than the maximum power point, $\mathrm{dP} / \mathrm{dV}<0$ or $\mathrm{dI} / \mathrm{dV}$ $<-\mathrm{I} / \mathrm{V}$ and also the change in currents are equal to zero by which the increments are being added (or) subtracted from the duty cycle. Thus, the MPP tracker can know where the power-voltage curve is by calculating the relationship of change in current and voltage themselves.

\section{MPPT CONTROLLER WITH DC BOOST CONVERTER}

The proposed system structure with a DC boost converter is given to the inverter to drive the load. The PV array is made up of six 315 PV modules that are linked in series and parallel to provide higher output voltages and currents. 
The proposed MPPT control algorithm harvests the maximum power from a solar PV module and their characteristics are shown under a variety of circumstances in section IV.

\section{SPACE VECTOR PULSE WIDTH MODULATION TECHNIQUE}

The space vector PWM technique is an advanced computation-intensive PWM method this could be the best method for variable-frequency drive applications of all PWM techniques. Space Vector Pulse Width Modulation is a modulation scheme used to apply for given voltage vector to a three-phased AC-powered motor.
The objective is to simulate a three-phased sinusoidal waveform with adjustable frequency and amplitude using a steady-state DC supply and six switches.

A three-phase inverter transforms a DC supply to three output legs that may be linked to a three-phase motor through a set of switches. The switches must be programmed such that no two switches in the same leg are switched on at the same time, or the DC supply will be shorted. The complementary action of the switches inside a leg may be sufficient to meet this criterion. If $\mathrm{A}+$ is turned on, A is turned off, and vice versa. As a result, the inverter has eight potential switching vectors, V0 through V7, with six active switching vectors and two zero vectors.

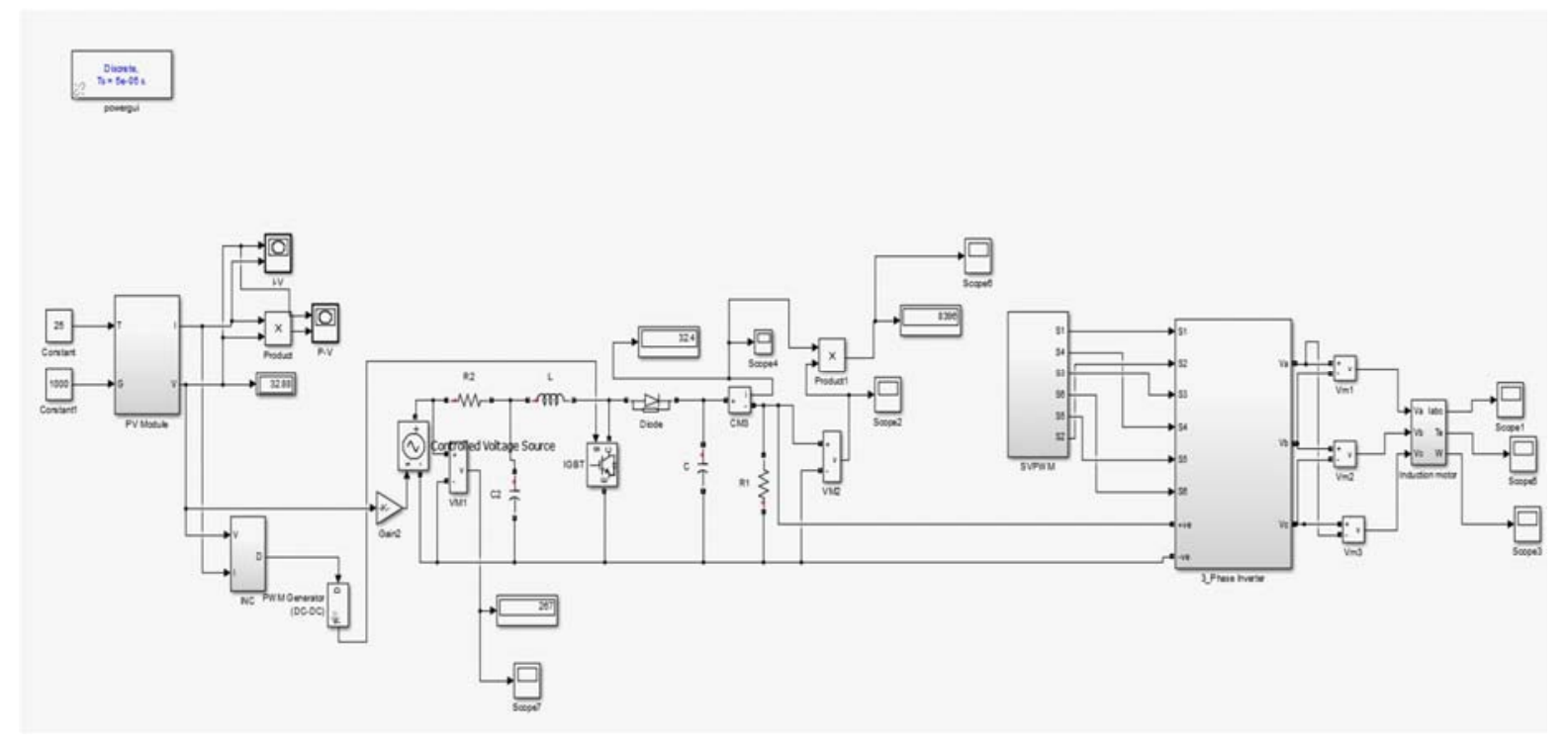

Fig.4 Block diagram representation of the designed model.

TABLE. III Eight possible Switching Vectors of the 3-ph Inverter

\begin{tabular}{|c|c|c|c|c|c|c|c|c|c|c|}
\hline VECTOR & $\mathrm{A}^{+}$ & $\mathrm{B}+$ & $\mathrm{C}+$ & $\mathrm{A}-$ & $\mathrm{B}-$ & $\mathrm{C}-$ & $V_{A B}$ & $V_{B C}$ & $V_{C A}$ & \\
\hline$V_{0}=\{000\}$ & OF & OF & OF & ON & ON & ON & 0 & 0 & 0 & Zero \\
\hline$V_{1}=\{100\}$ & ON & OF & OF & OF & ON & ON & $+V_{d c}$ & 0 & $-V_{d c}$ & Active \\
\hline$V_{2}=\{110\}$ & ON & ON & OF & OF & OF & ON & 0 & $+V_{d c}$ & $-V_{d c}$ & Active \\
\hline$V_{3}=\{010\}$ & OF & ON & OF & ON & OF & ON & $-V_{d c}$ & $+V_{d c}$ & 0 & Active \\
\hline$V_{4}=\{011\}$ & OF & ON & ON & ON & OF & OF & $-V_{d c}$ & 0 & $+V_{d c}$ & Active \\
\hline$V_{5}=\{001\}$ & OF & OF & ON & ON & ON & OF & 0 & $-V_{d c}$ & $+V_{d c}$ & Active \\
\hline$V_{6}=\{101\}$ & ON & OF & ON & OF & ON & OF & $+V_{d c}$ & $-V_{d c}$ & 0 & Active \\
\hline$V_{7}=\{111\}$ & ON & ON & ON & OF & OF & OF & 0 & 0 & 0 & Zero \\
\hline
\end{tabular}

The switching sector is represented as follows with six vectors along with the $\mathrm{d}$-axis and q-axis. The angle varies between the reference voltage and the sector of operation as we have a rotating magnetic field in space and its changes concerning the state of operation, which is shown as follows

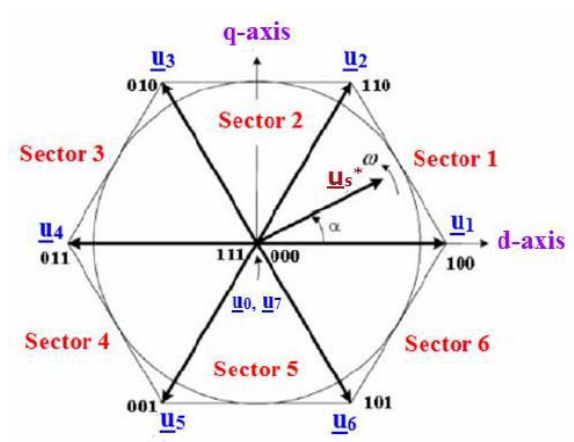

Fig.5 Representation of six sectors of SPWM technique 
The calculation for switching time duration at any sector is given as

$$
\begin{gathered}
T_{1}=\frac{\sqrt{3} \cdot T_{z} \cdot\left|V_{r e f}\right|}{V_{d c}}\left(\sin \left(\frac{\pi}{3}-\alpha+\frac{n-1}{3} \pi\right)\right) \\
=\frac{\sqrt{3} \cdot T_{z} \cdot\left|V_{r e f}\right|}{V_{d c}}\left(\sin \left(\frac{n \pi}{3}-\alpha\right)\right) \\
T_{2}=\frac{\sqrt{3} \cdot T_{z} \cdot\left|V_{r e f}\right|}{V_{d c}}\left(\sin \left(\alpha-\frac{n-1}{3} \pi\right)\right) \\
=\frac{\sqrt{3} \cdot T_{z} \cdot\left|V_{r e f}\right|}{V_{d c}}\left(-\cos \alpha \cdot \sin \frac{n-1}{3} \pi+\sin \alpha \cdot \cos \frac{n-1}{3} \pi\right)
\end{gathered}
$$

$T_{0}=T_{z}-T_{1}-T_{2}$, ((where $\mathrm{n}=1$ through 6 (that is, Sector 1 to 6$\left.)\left(0 \leq \alpha \leq 60^{\circ}\right)\right)$.

By considering the above switching times for each sector of switches. We give connection to the upper leg of switches and lower switches will be complimentary for them. Thus we obtain the six gate pulses from the SVPWM which are to be fed to the 3-phase inverter.

\section{E. MATHEMATICAL MODELLING OF THREE- PHASE ASYNCHRONOUS MOTOR}

It works on the principle of electromagnetic induction and there are some assumptions required for modeling of asynchronous motor they are given as

- Uniform air gap and windings are identical.

- Sinusoidally distributed MMF with balanced rotor and stator windings.

- Losses such as saturation, eddy current, friction, and windage are not taken into account.

The mathematical model of the 3-ph squirrel cage asynchronous motor consists of voltage, magnetic fluxes, and motion dynamical equations.

$$
\begin{aligned}
& V_{d s}=R_{s} \cdot i_{d s}-\omega_{1} \cdot L_{s} \cdot i_{q s}-\omega_{1} \cdot L_{m} \cdot i_{q r}+\frac{d \varphi_{d s}}{d t} \\
& V_{q s}=R_{s} \cdot i_{q s}-\omega_{1} \cdot L_{s} \cdot i_{d s}-\omega_{1} \cdot L_{m} \cdot i_{d r}+\frac{d \varphi_{q s}}{d t} \\
& 0=R_{r} \cdot i_{d r}-\left(\omega_{1}-\omega\right) \cdot\left(L_{r} \cdot i_{q r}+L_{m} \cdot i_{q s}\right)+\frac{d \varphi_{d r}}{d t} \\
& 0=R_{r} \cdot i_{q r}-\left(\omega_{1}-\omega\right) \cdot\left(L_{r} \cdot i_{d r}+L_{m} \cdot i_{d s}\right)+\frac{d \varphi_{q r}}{d t}
\end{aligned}
$$

Where $V_{d s}$ and $V_{q s}$ are $\mathrm{d}-\mathrm{q}$ axis stator voltages, respectively, $i_{d s}, i_{q s}$ and $i_{d r}, i_{q r}$ are d-q axis stator and rotor currents, respectively, $R_{s}$ and $R_{r}$ are stator and rotor resistance per phase. $L_{s}, L_{r}$ are self inductances of stator and rotor, and $L_{m}$ is mutual inductance. Where the rotor and stator magnetic fluxes in a $d-q$ reference frame:

$\varphi_{d s}=L_{s} i_{d s}+L_{m} \cdot i_{d r}$ $\varphi_{q s}=L_{s} i_{q s}+L_{m} \cdot i_{q r}$

$\varphi_{d r}=L_{r} i_{d r}+L_{m} \cdot i_{d s}$

$\varphi_{q r}=L_{r} i_{q r}+L_{m} \cdot i_{q s}$

The electromagnetic torque $T_{e}$ of the induction motor is given by:

$T_{e}=\frac{3}{2}\left(\frac{p}{2}\right)\left(\varphi_{q r} i_{d r}-\varphi_{d r} i_{q r}\right)$.

\section{RESULTS AND DISCUSSION}

Matlab Simulink has been used to create the required system model. Under standard test conditions (STC), we have 6 modules with 72 cells to produces 315 Watts of power. The I-V curve and P-V curve features of solar PV systems are depicted in Fig.6.

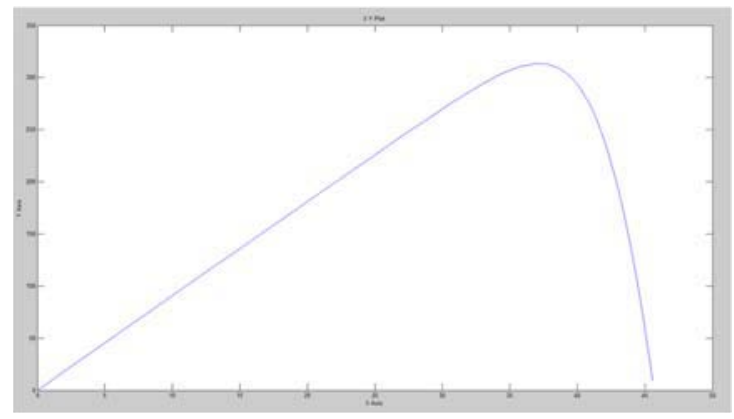

(a)

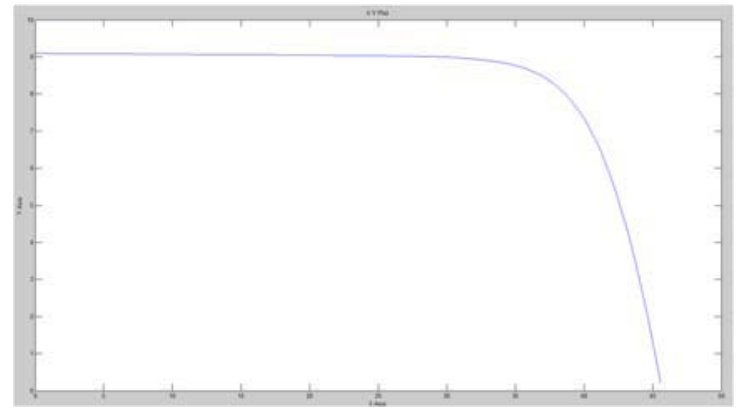

(b)

Fig.6 I-V \& P-V characteristics obtained from PV array

The maximum output power obtained from the practical working conditions of a PV array with the proposed MPPT controller from experimental validation at different times of day from morning $8 \mathrm{a} . \mathrm{m}$. to evening 4 p.m. is 2177.44 Watts, with a maximum voltage of 90.747 Volts and a current of about 23.994 Amps. Fig 7 depicts the locus of all the points. 


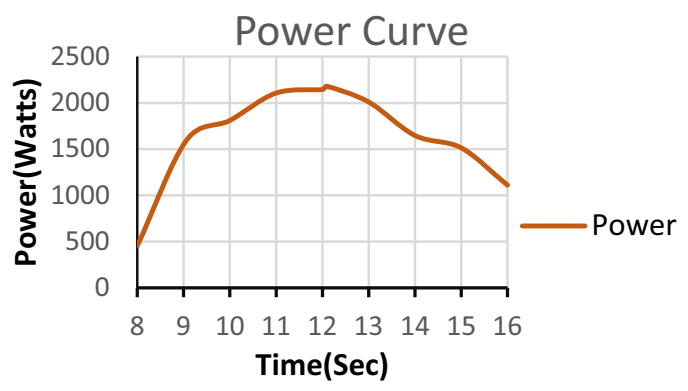

Fig.7 Practical output power of a PV array at different time instants

A. MPPT controller outputs for the module with dynamic Irradiance and static Temperature.

The module PV \& IV curves were plotted here we observe the PV current and voltage increases as irradiation levels rise. As a result, the net PV module power increases. These characteristics are shown in Fig.8.

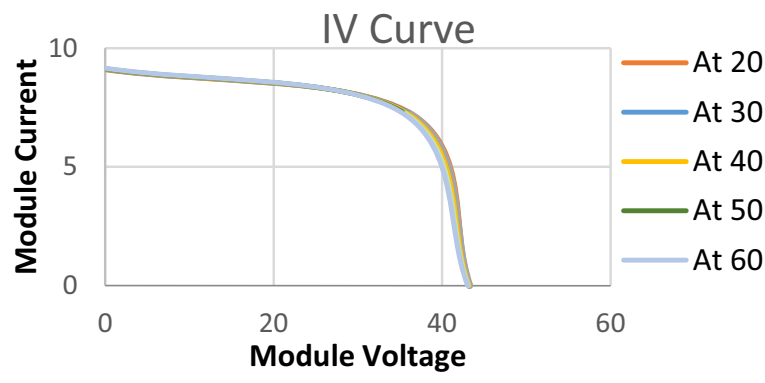

(a)

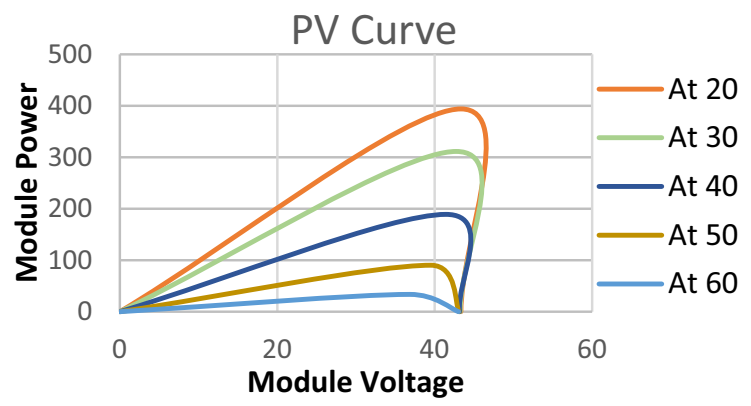

(b)

Fig.8 I-V \& P-V characteristics with variable irradiance and constant temperature for module

B. MPPT controller outputs for the array with dynamic Irradiance and static Temperature.

The array PV \& IV curves were plotted here we observe the PV current and voltage increases as irradiation levels rise. As a result, the power of the net PV array increases. These characteristics are shown in Fig.9.

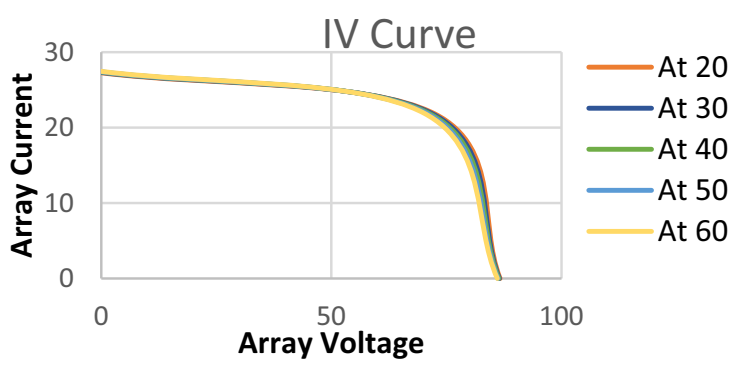

(a)

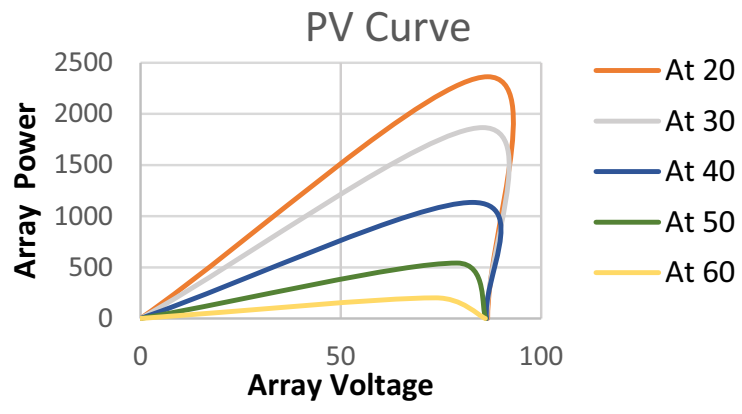

(b)

Fig.9 I-V \& P-V characteristics with variable irradiance and constant temperature for an array

C. MPPT Controller outputs for the module with Dynamic Temperature and Static Irradiance.

The module PV \& IV curve were plotted we observe a dramatic reduction in PV module voltage and it boosts PV current slightly. As a result, the output power of net PV modules decreases. Fig.10 depicts these characteristics.

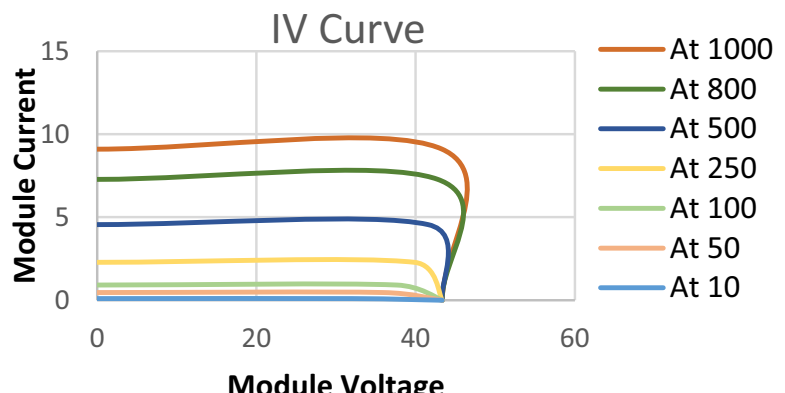

(a)

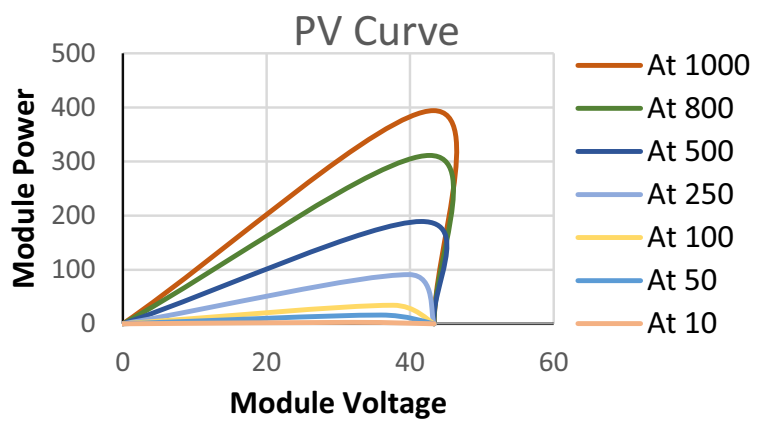

(b) 
Fig.10 I-V \& P-V characteristics with variable temperature and constant irradiance for module

D. MPPT Controller outputs for the array with Dynamic Temperature and Static Irradiance.

The module PV \& IV curve were plotted we observed a significant reduction in PV array voltage, it is discovered that it boosts PV current slightly. As a result, the output power of the net PV array decreases. Figure 11 depicts these characteristics.
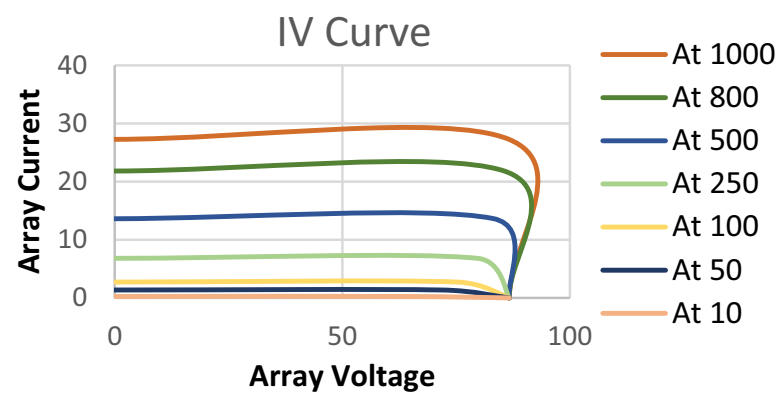

(a)
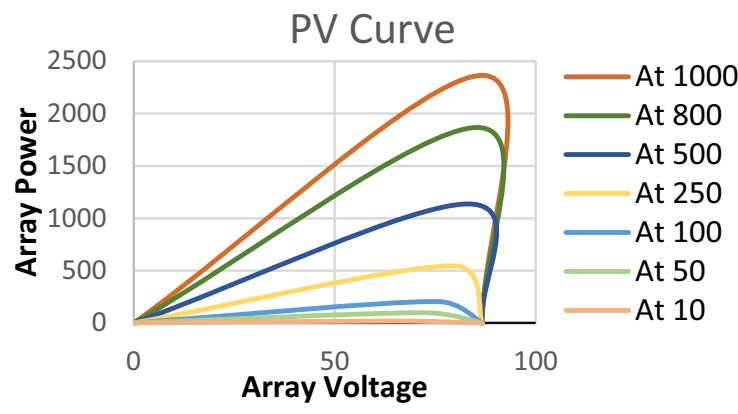

(b)

Fig.11 I-V \& P-V characteristics with variable temperature and constant irradiance for an array.

E. Simulation results of Asynchronous motor drive.

Simulation results are obtained with a reference speed of $3000 \mathrm{rpm}$ and a switching frequency of $5 \mathrm{kHz}$. The
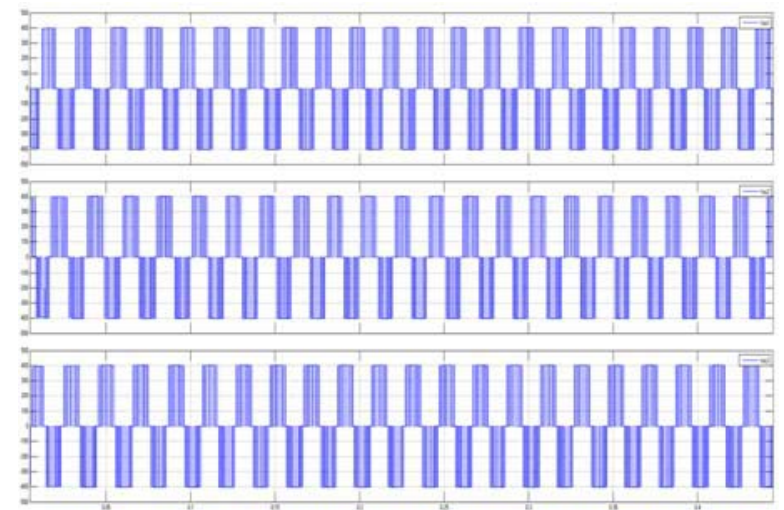

Fig.12 Output voltage of inverter. behaviour of motor parameters such as stator phase current, torque, and speed are illustrated below with parameter values as $\mathrm{Rs}=0.200 \Omega, \mathrm{Rr}=0.158 \Omega, \mathrm{Ls}=$ $0.0425 \mathrm{H}, \mathrm{Lm}=0.0412 \mathrm{H}, \mathrm{Lr}=0.0418 \mathrm{H}, \mathrm{J}=0.1, \mathrm{P}=2, \mathrm{f}=$ $50 \mathrm{~Hz}$. Here the motor drive is being fed with help of boost converter and inverter. The output voltage of inverter represented above in fig. 12 .

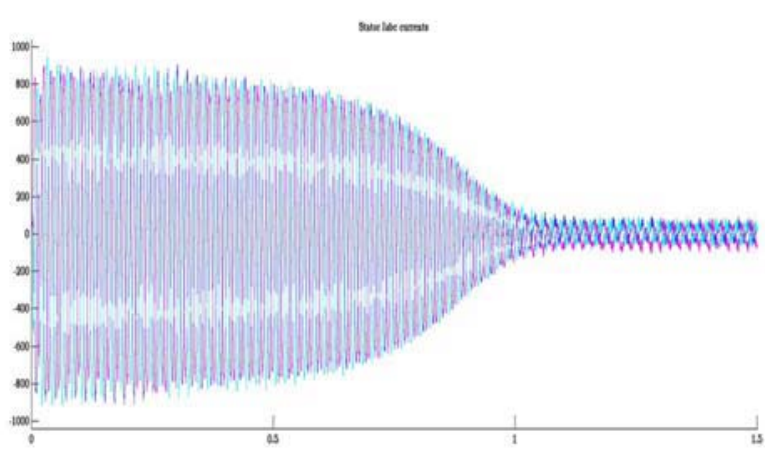

Fig.13 Stator phase currents of induction motor.

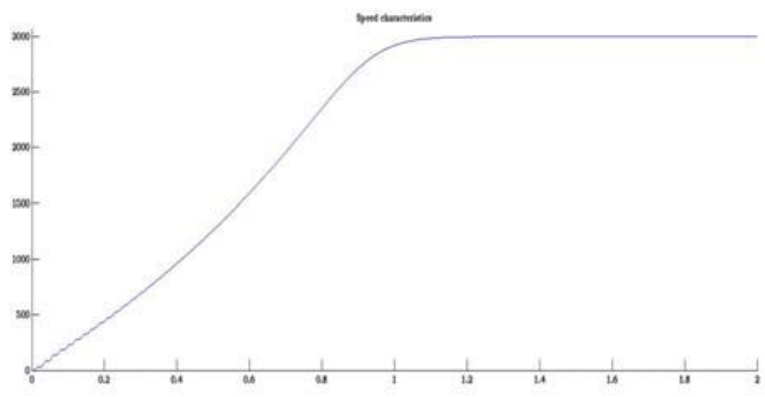

Fig.14 Characteristics of speed

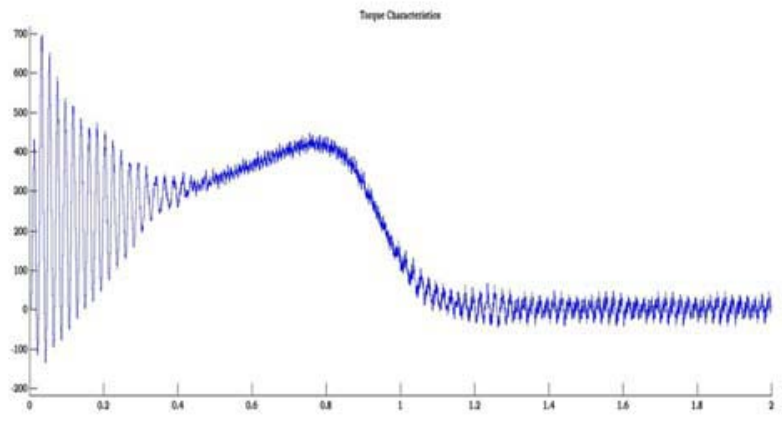

Fig.15 Characteristics of torque.

As THD of stator phase currents is $3.92 \%$ that the ripple content is reduced and obtained better performance of the drive. 


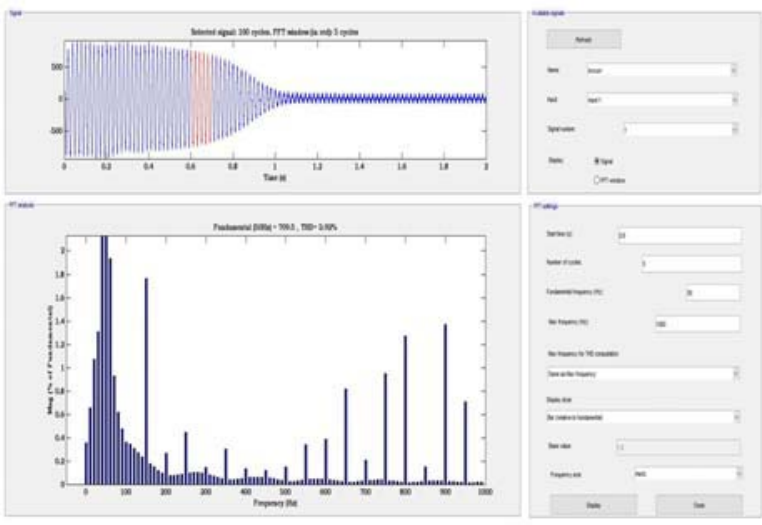

Fig.16 THD for Iabc currents

F. Comparitive analysis on the proposed model.

Comparing the P \& O method which was existed earlier to the proposed methodology i.e., in the $\mathrm{P} \& \mathrm{O}$ method the Voc of $75.96 \mathrm{~V}$ and Isc current of $26.01 \mathrm{~A}$ were used to achieve max power at MPP as 1500 watts but the Incremental method has Voc of $45.70 \mathrm{~V}$ and Isc of $9.10 \mathrm{~A}$ is used to obtain max power at MPP as 2177.44 watts that we are achieving more power compared to other methods [7]. When compared to the ANN method in [17] the speed and torque response of the proposed model obtained were faster as shown in fig. 14 and fig. 15.

\section{CONCLUSION}

Hence, by using the incremental conductance MPPT controller we are increasing the performance of the boost converter. Through which we fed to the 3 -phase inverter and also using the space vector pulse width modulation to the inverter to further reduce the ripple contents in torque and speed characteristics. The PV system modeling at different climatic conditions i.e., constant temperature and variable irradiance and also constant irradiance and variable temperature were observed and presented in section 4.

\section{References}

[1] R. Faranda, S. Leva, WSEAS Transactions on Power Systems, 3(6):446-55, (2008).

[2] A. Mellit, S. A. Kalogirou, A Review Progress in Energy and Combustion Science, (2008).

[3] M. B. Shadmand, M. Mosa, R. S. Balog, H. Abu rub, IEEE Applied Power Electronics Conference and Exposition (APEC), pp. 3067-3074, (2015).
[4] Mamta suthar, G. K. Singh, and R. P. Saini, IEEE (ICEETS) International Conference, pp. 1354-1359, (2013).

[5] S. Nema, R. K. Nema, and G. Agnihotri, International Journal of Energy and Environment, Volume 1, pp. 487-500, (2010).

[6] Jong-Pil. Lee, Byung-Duk. Min, Tae-Jin. Kim, DongWook. Yoo, and Ji-Yoon. Yoo, IEEE Transactions on Industrial Electronics, volume 55, no.7, pp. 26552663, (2008).

[7] M. Adly, M. Ibrahim and H. El sherif, IEEE (APPEEC), pp. 1-5, (2012).

[8] Q. Mei, M. Shan, L. Liu, and M. Josep guerrero, IEEE Transactions on Industrial Electronics, volume 58, no.6, pp. 2427-2434, (2011).

[9] B. Pakkiraiah, G. Durga Sukumar, IEEE (ICRCICN), pp. 294-299, (2015).

[10] B. Subudhi, and R. Pradhan, IEEE Transactions on Sustainable Energy, volume 4, no.1, pp. 89-98, (2013).

[11] S. Jie, L. Wei-Jen, L. Yongqian, Y. Yongping, and P. Wang, IEEE Transactions on Industry Applications, volume 48, no.3, pp. 1064-1069, (2012).

[12] M. B. Shadmand, R. S. Balog and M. D. Johnson, IEEE Transactions on Sustainable Energy, volume 5, no.4, pp. 1434-1442, (2014).

[13] T. Esram and P. L. Chapman, IEEE Transactions on Energy Conversion, volume 22, no.2, pp. 439-449, (2007).

[14] B. Pakkiraiah, G. Durga Sukumar, J. Sol. Energy, doi:10.1155/ 2016/8012432, (2016).

[15] Joshi, J. J. Karthick, P. Kumar, IEEE (ICEETS), pp. 1201-1206, (2013).

[16] Aleenejad, M. Iman-Eini, H. Farhangi, In IEEE $20^{\text {th }}$ (ICEE), pp. 546-551, (2012).

[17] B. Pakkiraiah, G. Durga Sukumar, Indian Journal of science and technology, Volume 9(45), (2016).

[18] C. Sreeja, S. Arun, IEEE PES (ISGT India), (2011).

[19] B. Pakkiraiah, G. D. Sukumar, International Journal of Computers and Applications-Taylor and Francis, (2016).

[20] A. Mbarushimana, X. Ai, IEEE International Conference on Electric Utility Dereglation and Restructuring and Power Technologies, (2011) 